\title{
IL-6 and TNF- $\alpha$ promote metastasis of lung cancer by inducing epithelial-mesenchymal transition
}

\author{
GUAN-SHENG SHANG ${ }^{1}$, LUNXU LIU ${ }^{1}$ and YI-WEI QIN ${ }^{2}$ \\ ${ }^{1}$ Department of Thoracic Surgery, West China School of Medicine, Sichuan University, Chengdu, Sichuan 610041; \\ ${ }^{2}$ Department of Intensive Medicine, The First Affiliated Hospital of Chengdu Medical College, \\ Chengdu, Sichuan 610500, P.R. China
}

Received August 5, 2016; Accepted February 9, 2017

DOI: $10.3892 / \mathrm{ol} .2017 .6048$

\begin{abstract}
The characteristics of cancer cells, such as invasiveness, are affected by the tumor microenvironment. Studies have shown that interleukin (IL)- 6 and tumor necrosis factor (TNF)- $\alpha$ regulate the proliferation of lung cancer. However, few studies have focused on the effects of IL- 6 and TNF- $\alpha$ on metastasis of lung cancer. The present study was designed to investigate whether IL- 6 and TNF- $\alpha$ can promote metastasis of non-small cell lung cancer (NSCLC). Sixty-five tumor and matched adjacent tissue samples from patients with NSCLC and corresponding serum samples were collected. Thirty serum samples from healthy subjects were selected as controls. Real-time PCR and western blot analysis were used to measure IL- 6 , TNF- $\alpha$, vimentin, E-cadherin, and N-cadherin expression in tissue samples; ELISA was used to measure IL-6 and TNF- $\alpha$ expression in serum samples. The correlation of serum levels of IL-6 and TNF- $\alpha$ with the clinical stage was analyzed; the correlation of IL- 6 and TNF- $\alpha$ levels in serum with these tissues was analyzed; the correlation of serum levels of IL- 6 and TNF- $\alpha$ with lymph node metastasis and distant metastasis was analyzed. Expression of IL- 6 and TNF- $\alpha$ were significantly increased compared with controls in both serum and tissue; IL- 6 and TNF- $\alpha$ levels were positively correlated with lymph node metastasis and distant metastasis; IL-6 and TNF- $\alpha$ levels were negatively correlated with E-cadherin level and were positively correlated with $\mathrm{N}$-cadherin and vimentin levels. In conclusion, IL-6 and TNF- $\alpha$ can induce epithelial-mesenchymal transition, and subsequently promote metastasis of lung cancer. Anti-inflammation should be considered for the treatment of lung cancer.
\end{abstract}

Correspondence to: Dr Lunxu Liu, Department of Thoracic Surgery, West China School of Medicine, Sichuan University, 37 Guoxue Lane, Chengdu, Sichuan 610041, P.R. China

E-mail: lunxu_liu@aliyun.com

Key words: lung cancer, epithelial-mesenchymal transition, interleukin-6, tumor necrosis factor- $\alpha$

\section{Introduction}

With increasing air pollution, the incidence rate of lung cancer has been increasing annually and ranks first among all malignant tumors (1). Among lung cancers, non-small cell lung cancer (NSCLC) accounts for 80\%, with chemotherapy as the main treatment method (2). Early invasion and metastasis of tumors and drug resistance are important factors that influence the effect of treatment, showing only a $15 \%$ 5-year survival rate (3). A previous study showed that the subpopulation of tumor cells known as 'tumor stem cells' are capable of invasion and have natural drug-resistance or the ability to acquire drug resistance after mutations (4). Previous cell and animal models proved that NSCLC tumors can secrete interleukin (IL)-6 and tumor necrosis factor (TNF)- $\alpha$, which promote proliferation and differentiation of tumor cells. In contrast, there are few studies on the ability of these molecules to regulate invasion and migration (5). As an initiating factor of distant metastasis of malignant tumors, the main feature of the epithelial-mesenchymal transition (EMT) is the change of cell phenotype, including the downregulation of epithelial markers such as E-cadherin, loss of cell polarity, upregulation of vimentin and $\mathrm{N}$-cadherin, the acquisition of expression of other mesenchymal markers, and increased migration and mobility, thus promoting the invasion and metastasis of malignant epithelial tumor cells $(6,7)$. NSCLC is mainly derived from the bronchial and alveolar epithelium, therefore it is speculated that EMT plays an important role in the biological behavior of NSCLC. Based on this hypothesis, the present study was designed to analyze the ability of IL- 6 and TNF- $\alpha$ to promote EMT and in turn NSCLC, to provide a reference for clinical diagnosis, treatment, and prognosis of patients with NSCLC.

\section{Patients and methods}

Patients. Sixty-five patients who were admitted to the First Affiliated Hospital of Chengdu Medical College for primary diagnosis of NSCLC from January 2014 to January 2016 were consecutively selected and had pathologically-confirmed disease. Patients who underwent surgery or radiotherapy, had history of chemotherapy, or cases with other pulmonary diseases such as chronic obstructive pulmonary disease and phthisis were excluded. Among patients, there were 37 males 
Table I. Gene primer sequences.

\begin{tabular}{lll}
\hline Gene & \multicolumn{1}{c}{ Sequences } & bp \\
\hline IL-6 & F: 5'-GAAAACACCAGGGTCAGCAT-3' & \\
& R: 5'-CAGCCACTGGTTTTTCTGCT-3' & 153 \\
TNF- $\alpha$ & F: 5'-CTCCTACCCGAACAAGGTCA-3' & \\
& R: 5'-CGGTCACCCTTCTCCAACT-3' & 138 \\
Vimentin & F: 5'-TGGCCGACGCCATCAACACC-3' & \\
& R: 5'-CACCTCGACGCGGGCTTTGT-3' & 145 \\
E-cadherin & F: 5'-TGAAGGTGACAGAGCCTCTGGA-3' \\
& R: 5'-TGGGTGAATTCGGGCTTGTT-3' & 152 \\
N-cadherin & F: 5'-GCGCGTGAAGGTTTGCCAGTG-3' & \\
& R: 5'-CCGGCGTTTCATCCATACCACAA-3' & 156 \\
3-actin & F: 5'-GAATCCACTGGCGTCTTCAC-3' & \\
& R: 5'-CGTTGCTGACAATCTTGAGAGA-3' & 160 \\
& &
\end{tabular}

IL-6, interleukin-6; TNF- $\alpha$, tumor necrosis- $\alpha$.

and 28 females, with average age of $56.7 \pm 12.3$ years. According to TNM staging, the patients were divided into seven cases of stage I, 18 cases of stage II, 22 cases of stage III, and 18 cases of stage IV. Additionally, 30 healthy subjects were selected as the control group during the same period, including 15 males and 15 females, with average age of $55.8 \pm 14.6$ years. The study obtained the approval of the Ethics Committee of the First Affiliated Hospital of Chengdu Medical College and written informed consent of the patients or their families was obtained.

Research methods. Tumor tissue and adjacent tissue (away from the tumor resection margin with negative character, by at least $5 \mathrm{~cm}$ ) specimens were obtained from patients with NSCLC, which were used for preparing paraffin sections. In addition, $5 \mathrm{ml}$ peripheral venous blood from patients with NSCLC and the control group were collected, and the supernatant was harvested after centrifugation at 2,000 $\mathrm{x}$ g for $20 \mathrm{~min}$, and stored at $-20^{\circ} \mathrm{C}$. The levels of IL-6, TNF- $\alpha$, vimentin, $\mathrm{E}$-cadherin, and $\mathrm{N}$-cadherin in tissue samples were measured by RT-PCR and western blot analysis, while the levels of serum IL- 6 and TNF- $\alpha$ were measured by enzyme-linked immunosorbent assay (ELISA).

$R T-P C R$. Total RNA was extracted with the Qiagen RNeasy mini kit (Qiagen, Berlin, Germany), and the concentration and purity were determined by spectrophotometry. A total of $4,000 \mathrm{ng}$ RNA was used for reverse transcription. The reaction system included $5 \mu \mathrm{l}$ AMV reverse transcriptase $5 \mathrm{X}$ reaction buffer $+2.5 \mu \mathrm{l}$ dNTPs $(10 \mathrm{mmol} / \mathrm{l})+40 \mathrm{U}$ ribonuclease inhibitor $+150 \mathrm{ng}$ of each Oligo d(T)15 Primer and random primers + $30 \mathrm{U}$ AMV reverse transcriptase + RNase-free water for a total volume of $25 \mu \mathrm{l}$. The reaction was allowed to proceed for $60 \mathrm{~min}$ in a $42^{\circ} \mathrm{C}$ water bath. The IL-6, TNF- $\alpha$, vimentin, $\mathrm{E}$-cadherin, $\mathrm{N}$-cadherin, and $\beta$-actin gene sequences were retrieved from NCBI (Table I), primers were designed with Primer Premier 5.0, and synthesized by Bao Biological Engineering Co., Ltd. (Dalian, China). The reaction system included $12.5 \mu 12 \mathrm{X}$ Master Mix $+1 \mu \mathrm{l}$ of each primer (upstream

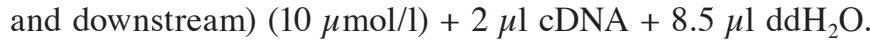
The thermal profile was $95^{\circ} \mathrm{C}$ for $30 \mathrm{sec}, 95^{\circ} \mathrm{C}$ for $5 \mathrm{sec}$, and $63^{\circ} \mathrm{C}$ for $30 \mathrm{sec}$, for a total of 40 cycles. Gene expression was calculated according to the $2^{-\Delta \Delta C q}$ method.

Western blot analysis. Total protein from whole tissue samples were extracted according to the instructions of the protein-isolation kit (KangChen Bio-tech, Inc., Shanghai, China). A BCA protein concentration kit (Beijing Biyuntian Technology Co., Ltd., Beijing, China; microplate reader EXL $800 \mathrm{UV}$ was purchased from BioTek Instruments, Inc., Winooski, VT, USA) was used to measure protein concentration. Samples were loaded on gels and separated by SDS-PAGE (separation gel voltage was $120 \mathrm{~V}$ ) for $2 \mathrm{~h}$ (electrophoresis instrument was from Bio-Rad Laboratories, Inc., Hercules, CA, USA). A semi-dry transmembrane instrument (Bio-Rad Laboratories, Inc.) was used for transferring samples to PVDF membranes. PVDF membranes were placed in blocking solution (5\% dried skimmed milk in TBST) on a rocking platform for $1 \mathrm{~h}$ at room temperature. TBST was used to wash membranes three times for $10 \mathrm{~min}$. Membranes were then sealed in valve bags containing mouse monoclonal IL-6 antibody (dilution, 1:200; cat. no. 12153), mouse monoclonal TNF- $\alpha$ antibody (dilution, 1:200; cat. no. 11948), mouse monoclonal vimentin antibody (dilution, 1:500; cat. no. 3390), mouse monoclonal E-cadherin antibody (dilution, 1:500; cat. no. 5296), mouse monoclonal N-cadherin antibody (dilution, 1:500; cat. no. 14215) or mouse monoclonal $\beta$-actin antibody (dilution, 1:50; cat. no. 12262) monoclonal primary antibodies (Cell Signaling Technology, Inc., Danvers, MA, USA), and allowed to incubate with shaking for $2 \mathrm{~h}$ at $4^{\circ} \mathrm{C}$. Membranes were then washed three times for 10 min with TBST. Next, membranes were incubated with goat anti-mouse secondary antibody (dilution, 1:10,000; cat. no. 926-65010) solution (LI-COR Biosciences, Lincoln, NE, USA) for $30 \mathrm{~min}$ at room temperature. PVDF membranes were then placed in TBST buffer while shielded from light. A computer imaging system (Odyssey Imager; LI-COR Biosciences $\mathrm{GmbH}$ ) was used to analyze protein expression.

ELISA. IL-6 and TNF- $\alpha$ ELISA kits were from Sigma-Aldrich (St. Louis, MO, USA), and experiments were performed according to the manufacturer's instructions. Values were averaged after repeating the experiments twice.

Statistical analysis. SPSS 20.0 software (IBM, Armonk, NY, USA) was used for statistical analysis. Measurement data are presented as mean \pm standard deviation, independent sample t-test was used for inter-group comparisons, and paired t-test was used for comparisons within groups. A Pearson's test was used for correlation analyses after normality tests. $\mathrm{P}<0.05$ was considered to indicate a statistically significant difference.

\section{Results}

Comparison of IL- $6, T N F-\alpha$, vimentin, E-cadherin, and $N$-cadherin mRNA expression in tissue samples. IL-6, TNF- $\alpha$, vimentin, and $\mathrm{N}$-cadherin mRNA expression levels in tumor tissues were significantly higher compared with adjacent 
Table II. Comparison of IL-6, TNF- $\alpha$, vimentin, E-cadherin, and N-cadherin mRNA expression in tissue samples.

\begin{tabular}{lccccc}
\hline Groups & IL-6 & TNF- $\alpha$ & Vimentin & E-cadherin & N-cadherin \\
\hline Tumor tissues & $0.5264 \pm 0.1259$ & $0.4284 \pm 0.1321$ & $0.5321 \pm 0.1524$ & $0.1252 \pm 0.0326$ & $0.4629 \pm 0.1022$ \\
Adjacent tissues & $0.1203 \pm 0.0527$ & $0.1523 \pm 0.0326$ & $0.2262 \pm 0.0527$ & $0.3529 \pm 0.1215$ & $0.1152 \pm 0.0629$ \\
t-test & 4.623 & 4.235 & 4.827 & 3.629 & 3.957 \\
P-value & 0.024 & 0.028 & 0.022 & 0.035 & 0.031 \\
\hline
\end{tabular}

IL-6, interleukin-6; TNF- $\alpha$, tumor necrosis- $\alpha$.

Table III. Comparison of IL-6, TNF- $\alpha$, vimentin, E-cadherin, and N-cadherin protein expression in tissue samples.

\begin{tabular}{|c|c|c|c|c|c|}
\hline Groups & IL-6 & TNF- $\alpha$ & Vimentin & E-cadherin & $\mathrm{N}$-cadherin \\
\hline Tumor tissues & $0.76 \pm 0.16$ & $0.62 \pm 0.14$ & $0.64 \pm 0.13$ & $0.23 \pm 0.09$ & $0.66 \pm 0.22$ \\
\hline Adjacent tissues & $0.24 \pm 0.07$ & $0.22 \pm 0.08$ & $0.19 \pm 0.06$ & $0.75 \pm 0.18$ & $0.23 \pm 0.10$ \\
\hline t-test & 5.123 & 4.785 & 4.925 & 5.234 & 5.426 \\
\hline P-value & 0.018 & 0.024 & 0.020 & 0.016 & 0.013 \\
\hline
\end{tabular}

IL-6, interleukin-6; TNF- $\alpha$, tumor necrosis- $\alpha$.

Table IV. Comparison of serum IL-6 and TNF- $\alpha$ level (ng/l).

\begin{tabular}{lcccc}
\hline Groups & NSCLC group & Control group & Tumor metastasis in NSCLC group & No metastasis \\
\hline IL-6 & $234.6 \pm 43.8$ & $54.7 \pm 12.5$ & $336.2 \pm 52.6$ & $152.8 \pm 25.9$ \\
TNF- $\alpha$ & $86.4 \pm 12.3$ & $12.6 \pm 5.6$ & $126.4 \pm 16.7$ & $35.2 \pm 8.2$ \\
\hline
\end{tabular}

IL-6, interleukin-6; TNF- $\alpha$, tumor necrosis- $\alpha$. NSCLC, non-small cell lung cancer.

tissues, and E-cadherin mRNA expression level was significantly decreased $(\mathrm{P}<0.05)$ (Table II).

Comparison of IL-6, TNF- $\alpha$, vimentin, E-cadherin and $N$-cadherin protein expression in tissue samples. IL-6, TNF- $\alpha$, vimentin, and $\mathrm{N}$-cadherin protein expression levels in tumor tissues were significantly higher than in adjacent tissues, and E-cadherin protein expression level decreased significantly $(\mathrm{P}<0.05)$ (Table III).

Comparison of serum IL- 6 and TNF- $\alpha$ levels. The levels of serum IL-6 and TNF- $\alpha$ in patients with NSCLC were significantly higher than those of the control group, and the differences were statistically significant $(\mathrm{P}<0.05)$. Among patients with NSCLC, there were 24 cases with lymph node or distant metastasis (36.9\%), and the levels of serum IL-6 and TNF- $\alpha$ were significantly higher than in patients without metastasis $(\mathrm{P}<0.05)$ (Table IV).

Correlation analysis. The levels of serum IL-6 and TNF- $\alpha$ level were correlated with the levels of IL-6, TNF- $\alpha$, vimentin, E-cadherin, and N-cadherin mRNA and protein in tumor tissue. Serum IL-6 and TNF- $\alpha$ levels were positively correlated with IL-6, TNF- $\alpha$, vimentin, and N-cadherin mRNA and protein levels, while they were negatively correlated with E-cadherin mRNA and protein levels.

\section{Discussion}

EMT is the transition from epithelial cells to mesenchymal cells. It is characterized by decreased expression or loss of epithelial cell markers, such as E-cadherin and keratin, and increased expression of mesenchymal cell markers, such as vimentin and $\mathrm{N}$-cadherin. Changes in cell morphology that decrease adhesiveness caused by rearrangements of the cytoskeletal system of tumor cells allow them to easily break away from primary lesions, thus invading and metastasizing to surrounding tissues (8). Therefore, EMT is an important mechanism involved in tumor metastasis. This study showed that the levels of vimentin and $\mathrm{N}$-cadherin mRNA and protein in tumor tissues of patients with NSCLC were significantly higher than those of adjacent tissues, while E-cadherin expression level decreased significantly. These observations were consistent with a previous study (9). Furthermore, it was previously shown that EMT is related to the invasion and metastasis ability of tumors in liver, breast, prostate and colorectal cancer (10). Tumor stem cells can manifest the characteristics of extremely active EMT (11). Moreover, p38, 
AKT/ $\beta$-catenin, and Wnt5a signaling pathways participate in the occurrence of EMT in tumor stem cells. Inhibiting key signaling molecules in these pathways can significantly inhibit EMT activity and increase the apoptosis or necrosis of tumor cells $(12,13)$.

The occurrence of EMT is closely associated with the tumor microenvironment and inflammation (14). Mesenchymal stem cells (MSCs), which have multiple differentiation potential and specific chemotaxis toward tumor tissue, can be used as carriers for targeted delivery of suicide genes, growth factor inhibitors, and oncolytic viruses to tumor tissues (15). However, MSCs can also promote tumor growth by immune inhibition, promoting angiogenesis, and by other mechanisms (16). When stimulated by the tumor microenvironment or inflammatory mechanisms, MSCs can secrete IL-6 and TNF- $\alpha$, which promote the occurrence of EMT of tumor cells (17). The levels of expression of IL- 6 and TNF- $\alpha$ in the tumor tissues and sera from patients with NSCLC increased significantly with the clinical stage of the tumor; vimentin and N-cadherin mRNA and protein levels in tumor tissues increased significantly, while E-cadherin mRNA and protein levels decreased significantly; IL- 6 and TNF- $\alpha$ levels were positively correlated with vimentin and $\mathrm{N}$-cadherin mRNA and protein levels in tumor tissues, while they were negatively correlated with E-cadherin mRNA and protein levels. These results indicated that IL- 6 and TNF- $\alpha$ played important roles in the occurrence of EMT of tumors (18). Our results further demonstrated that serum levels of IL- 6 and TNF- $\alpha$ of patients with NSCLC with lymph node or distant metastasis were significantly higher than in patients without metastasis. A previous study showed that IL- 6 and TNF- $\alpha$ can promote the proliferation and differentiation of NSCLC and participate in invasion and metastasis, the intervention of which may represent a new method for the treatment of tumors (19). Treating A549 lung cancer cells with IL-6 and TNF- $\alpha$ antagonists can distinctly decrease vimentin and $\mathrm{N}$-cadherin expression and increase E-cadherin expression, which indicated that IL-6 and TNF- $\alpha$ have the potential to interfere with the biological characteristics of tumors (20).

In conclusion, IL-6 and TNF- $\alpha$ can promote EMT of lung cancer cells, and promote invasion and metastasis, which are associated with tumor recurrence and drug resistance. Inhibiting the expression of IL- 6 and TNF- $\alpha$ may represent a new method for the treatment of tumors.

\section{References}

1. Cheng TYD, Cramb SM, Baade PD, Youlden DR, Nwogu C and Reid ME: The international epidemiology of lung cancer: latest trends, disparities, and tumor characteristics. J Thorac Oncol 11: 1653-1671, 2016.

2. Sarries C, Haura EB, Roig B, Taron M, Abad A, Scagliotti G and Rosell R: Pharmacogenomic strategies for developing customized chemotherapy in non-small cell lung cancer. Pharmacogenomics 3: 763-780, 2002.

3. Sharma D, Newman TG and Aronow WS: Lung cancer screening: history, current perspectives, and future directions. Arch Med Sci 11: 1033-1043, 2015.
4. Pore M, Meijer C, de Bock GH, Boersma-van Ek W, Terstappen LW, Groen HJ, Timens W, Kruyt FA and Hiltermann TJ: Cancer stem cells, epithelial to mesenchymal markers, and circulating tumor cells in small cell lung cancer. Clin Lung Cancer 17: 535-542, 2016.

5. Shintani Y, Fujiwara A, Kimura T, Kawamura T, Funaki S, Minami M and Okumura M: IL-6 secreted from cancer associated fibroblasts mediates chemoresistance in non-small-cell lung cancer by increasing epithelial-mesenchymal transition signaling. J Thorac Oncol 11: 1482-1492, 2016.

6. Rahman MA, Barger JF, Lovat F, Gao M, Otterson GA and Nana-Sinkam P: Lung cancer exosomes as drivers of epithelial mesenchymal transition. Oncotarget 7: 54852-54866, 2016.

7. Emmons MF, Faião-Flores F and Smalley KS: The role of phenotypic plasticity in the escape of cancer cells from targeted therapy. Biochem Pharmacol 122: 1-9, 2016.

8. Fan Z, Jiang H, Wang Z and Qu J: Atorvastatin partially inhibits the epithelial-mesenchymal transition in A549 cells induced by TGF- $\beta 1$ by attenuating the upregulation of SphK1. Oncol Rep 36: 1016-1022, 2016.

9. Ninsontia C, Phiboonchaiyanan PP and Chanvorachote P: Zinc induces epithelial to mesenchymal transition in human lung cancer H460 cells via superoxide anion-dependent mechanism. Cancer Cell Int 16: 48, 2016.

10. Chen JS, Liang LL, Xu HX, Chen F, Shen SL, Chen W, Chen LZ, Su Q, Zhang LJ, Bi J, et al: miR-338-3p inhibits epithelial-mesenchymal transition and metastasis in hepatocellular carcinoma cells. Oncotarget: Jun 17, 2016 (Epub ahead of print).

11. Hsiao YJ, Su KY, Hsu YC, Chang GC, Chen JS, Chen HY, Hong QS, Hsu SC, Kang PH, Hsu CY, et al: SPANXA suppresses EMT by inhibiting c-JUN/SNAI2 signaling in lung adenocarcinoma. Oncotarget 7: 44417-44429, 2016.

12. Ge A, Ma Y, Liu YN, Li YS, Gu H, Zhang JX, Wang QX, Zeng XN and Huang M: Diosmetin prevents TGF- $\beta 1$-induced epithelial-mesenchymal transition via ROS/MAPK signaling pathways. Life Sci 153: 1-8, 2016.

13. Bo H, Zhang S, Gao L, Chen Y, Zhang J, Chang X and Zhu M: Upregulation of Wnt5a promotes epithelial-to-mesenchymal transition and metastasis of pancreatic cancer cells. BMC Cancer 13: 496, 2013.

14. Lee SO, Yang X, Duan S, Tsai Y, Strojny LR, Keng P and Chen Y: IL-6 promotes growth and epithelial-mesenchymal transition of $\mathrm{CD} 133^{+}$cells of non-small cell lung cancer. Oncotarget 7 : 6626-6638, 2016

15. Zhou HS, Su XF, Fu XL, Wu GZ, Luo KL, Fang Z, Yu F, Liu H, Hu HJ, Chen LS, et al: Mesenchymal stem cells promote pancreatic adenocarcinoma cells invasion by transforming growth factor- $\beta 1$ induced epithelial-mesenchymal transition. Oncotarget 7: 41294-41305, 2016.

16. Rhee KJ, Lee JI and Eom YW: Mesenchymal stem cell-mediated effects of tumor support or suppression. Int J Mol Sci 16: 30015-30033, 2015.

17. Wang Y, Fu B, Sun X, Li D, Huang Q, Zhao W and Chen X: Differentially expressed microRNAs in bone marrow mesenchymal stem cell-derived microvesicles in young and older rats and their effect on tumor growth factor- $\beta 1$-mediated epithelial-mesenchymal transition in HK2 cells. Stem Cell Res Ther 6: 185, 2015.

18. Kawata M, Koinuma D, Ogami T, Umezawa K, Iwata C, Watabe T and Miyazono K: TGF- $\beta$-induced epithelial-mesenchymal transition of A549 lung adenocarcinoma cells is enhanced by pro-inflammatory cytokines derived from RAW 264.7 macrophage cells. J Biochem 151: 205-216, 2012.

19. Song J, Feng L, Zhong R, Xia Z, Zhang L, Cui L, Yan H, Jia X and Zhang Z: Icariside II inhibits the EMT of NSCLC cells in inflammatory microenvironment via down-regulation of Akt/NF- $\kappa \mathrm{B}$ signaling pathway. Mol Carcinog 56: 36-48, 2016.

20. Yamauchi Y, Kohyama T, Takizawa H, Kamitani S, Desaki M, Takami K, Kawasaki S, Kato J and Nagase T: Tumor necrosis factor-alpha enhances both epithelial-mesenchymal transition and cell contraction induced in A549 human alveolar epithelial cells by transforming growth factor-beta1. Exp Lung Res 36: 12-24, 2010. 